\title{
Recent Developments at the NASA Langley Research Center National Transonic Facility
}

\author{
Roman W. Paryz ${ }^{1}$ \\ NASA Langley Research Center, Hampton, VA 23681-2199
}

\begin{abstract}
Several upgrade projects have been completed or are just getting started at the NASA Langley Research Center National Transonic Facility. These projects include a new high capacity semi-span balance, model dynamics damping system, semi-span model check load stand, data acquisition system upgrade, facility automation system upgrade and a facility reliability assessment. This presentation will give a brief synopsis of each of these efforts.
\end{abstract}

\section{Nomenclature}

$\begin{array}{ll}\text { ARRA } & \text { American Recovery and Reinvestment } \\ & \text { Act } \\ \text { ATP } & =\text { Aeronautics Test Program } \\ \text { ATS } & =\text { Automatic Test Sequencer } \\ { }^{\circ} \mathrm{C}, \mathrm{C} & =\text { Degrees Celsius } \\ \mathrm{cm} & =\text { centimeter } \\ \mathrm{CDR} & =\text { Critical Design Review } \\ \mathrm{CRM} & =\text { Common Research Model } \\ \mathrm{DAS} & =\text { Data Acquisition System } \\ \mathrm{DDAS} & =\text { Dynamic Data Acquisition System } \\ \mathrm{DOE} & =\text { Design Of Experiment } \\ { }^{\circ} \mathrm{F}, \mathrm{F} & =\text { Degrees Fahrenheit } \\ \mathrm{FAS} & =\text { Facility Automation System } \\ \mathrm{FRS} & =\text { Flow Reference System } \\ \mathrm{ft}, \mathrm{ft}^{2} & =\text { feet, square feet } \\ \mathrm{HMI} & =\text { Human Machine Interface } \\ \mathrm{Hp} & =\text { Horsepower } \\ \mathrm{HQ} & =\text { Headquarters } \\ \mathrm{Hz}, \mathrm{KHz} & =\text { Hertz, Kilohertz } \\ \mathrm{in} . \mathrm{in} & =\text { Inches, Square inches } \\ \mathrm{K} & =\text { thousand } \\ \mathrm{Kg} & =\text { Kilogram } \\ \mathrm{KPa}, \mathrm{Pa} & =\text { Kilo Pascals, Pascals } \\ \mathrm{LaRC} & =\text { Langley Research Center } \\ \mathrm{lbs} & =\text { pounds } \\ \mathrm{lbs}-\mathrm{in} & =\text { pound-inches } \\ \mathrm{lbs} / \mathrm{sec} & =\text { pounds per second } \\ \mathrm{lbm} / \mathrm{sec} & =\text { pounds mass per second } \\ & \end{array}$

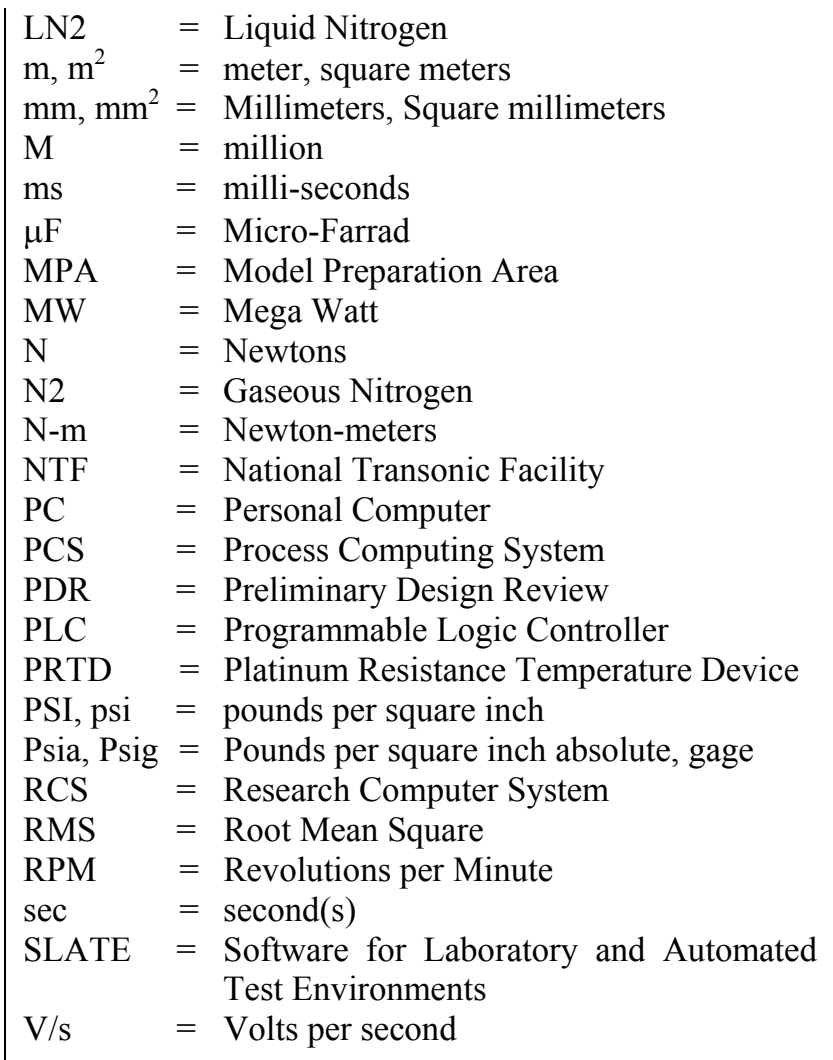

\section{Introduction}

The National Transonic Facility (NTF) is a fan-driven, closed-circuit, continuous-flow cryogenic pressurized wind tunnel that became operational in 1984 (Fig. 1). The facility has the capability to adjust test conditions to match model size and has independent control of total temperature, pressure, and fan speed allow isolation and study of pure compressibility (Mach) effects, viscous (Reynolds number) effects, and aero-elastic (dynamic pressure)

\footnotetext{
${ }^{1}$ Facility Manager, National Transonic Facility, AIAA Associate Fellow
} 
effects. Combinations of these test parameters can yield Reynolds numbers from 2 to145 million per foot (6.6 to 475.7 million per meter) (Fig. 2). The test section is approximately 8.2 feet ( 2.5 meter) by 8.2 feet ( 2.5 meter) and 25 feet (7.6 meter) long with a cross sectional area of $66.8 \mathrm{ft}^{2}\left(6.2 \mathrm{~m}^{2}\right)$. The test section has six slots in the ceiling, six slots in the floor, 14 re-entry flaps in the top and bottom walls to prevent the flow from choking the tunnel at nearsonic conditions, and a $6 \%$ openness ratio based on the wall surface area (wall divergence set at zero). See reference 1. NTF can be operated using either air or nitrogen as the test medium. During air operations temperature is controlled by a water-fed heat exchanger located in the settling chamber. During nitrogen operations the temperature is controlled by evaporating liquid nitrogen which is dispersed into the tunnel circuit just upstream of the fan through 296 nozzles in 12 bundles at a maximum rate $1,100 \mathrm{lbs} / \mathrm{sec}(9,680$ gallons/sec; 36K liters/sec). 430 tons of LN2 is produced on site per day and

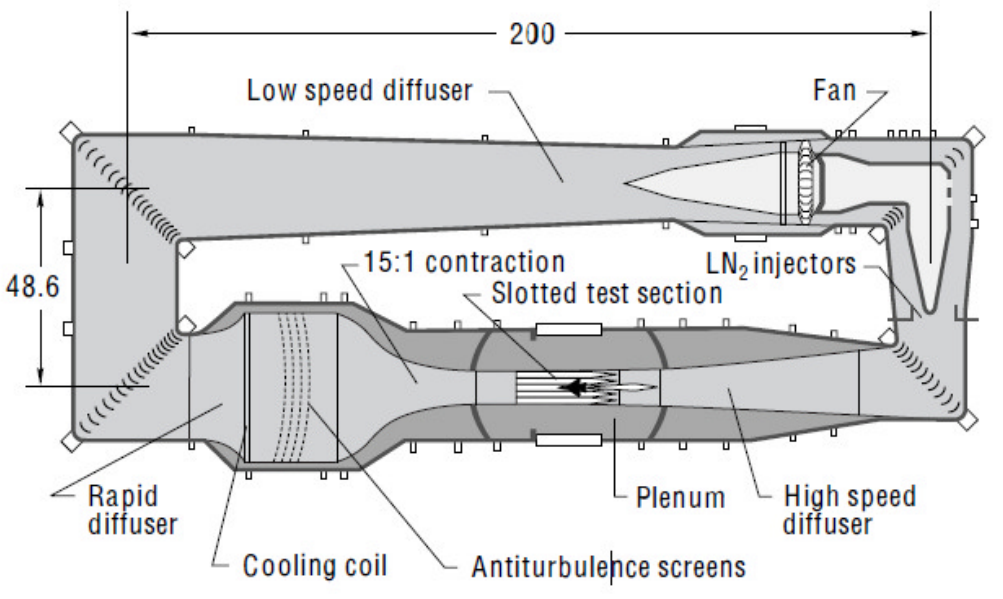

Figure 1. NTF Circuit Schematic. stored in two tanks with a total capacity of 3,800 tons $(1,150 \mathrm{M}$ gallons; $4.4 \mathrm{M}$ liters) These two modes provide the ability to operate the tunnel between $-250^{\circ} \mathrm{F}\left(-157^{\circ} \mathrm{C}\right)$ and $+150^{\circ} \mathrm{F}\left(+65^{\circ} \mathrm{C}\right)$. Thermal insulation that resides inside the pressure shell minimizes energy consumption. Pressure is controlled by two large vent valves connected to the tunnel circuit between turns \#3 and \#4. The facility can operate from $14.7 \mathrm{psia}(101.4 \mathrm{KPa})$ to $133 \mathrm{psia}(917.0 \mathrm{KPa})$ ( 1 to 9 atmospheres; 1.01 to 9.2 bar) in either medium. The tunnel drive system is powered by a variable speed motor that has variable maximum torque or power output up to $360 \mathrm{RPM}$. At $360 \mathrm{RPM}$ the maximum power is $135,000 \mathrm{Hp}(101 \mathrm{MW})$ and that maximum power level is maintained up to $600 \mathrm{RPM}$. The compressor consists of a fixed pitch, single stage 25 bladed fan with variable inlet guide vanes. For fine Mach number control, the inlet guide vanes are varied to achieve the required compression ratio to maintain the desired Mach number. Temperature can be maintained within $\pm 0.3^{\circ} \mathrm{F}\left(0.17^{\circ} \mathrm{C}\right)$ for $\mathrm{N} 2$ operations or $\pm 1^{\circ} \mathrm{F}\left(0.56^{\circ} \mathrm{C}\right)$ for air operations; Pressure $\pm 0.07 \mathrm{psi}$ (482 Pa); Mach no \pm 0.001 or better.

The NTF provides testing in support of stability and control, cruise performance, stall buffet onset, and configuration aerodynamics validation for both full-span and half-span models. The model support system is a circular arc sector that provides an angle-of-attack range of $-11.5^{\circ}$ to $19.0^{\circ}$ at a rate of up to $4^{\circ}$ per sec. The strut incorporates a roll drive with a range of $-90^{\circ}$ to $180^{\circ}$ which, in conjunction with the pitch of the strut, is able to provide pitch and yaw data. The normal force load capacity of the strut is $27,000 \mathrm{lbs}$. Several sting and strut combinations are available for testing of aerodynamic models. The NTF can accommodate various types of internal 6-component strain gage balances. Onboard angle-of-attack accelerometers are available that include thermal conditioning systems for cryogenic operation.

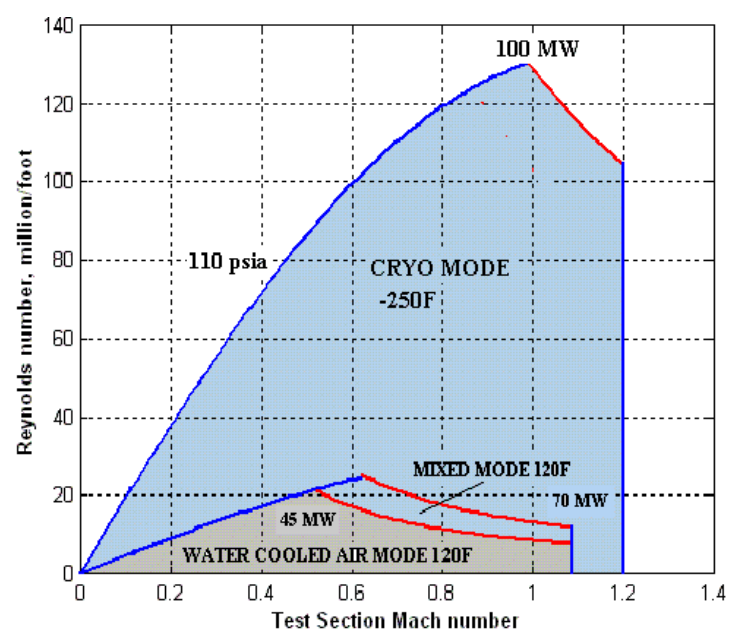

Figure 2. NTF Operating Map

\section{High Capacity Semi-Span Balance}

The semi-span model test technique at the NTF has traditionally focused on high-Reynolds number testing of low-speed high-lift configurations. The NTF-114S balance used for this testing is not well suited for transonic 
testing due to the elevated model loads generated. A larger load capacity balance, the NTF-117S was fabricated to obtain this high load data. See reference 2 .

The NTF-117S is a monolithic balance made from a single piece of high strength maraging steel (Fig 3). Its overall dimensions are approximately 16 inches $(40.64 \mathrm{~cm})$ in diameter by 25.75 inches $(65.41 \mathrm{~cm})$ long and it weighs approximately 900 pounds. It is a five-component balance, measuring normal force, axial force, pitching moment, rolling moment, and yawing moment (Table 1). The balance instrumentation consists of a primary and secondary set of strain gage bridges. Thirty-two platinum resistance temperature detectors (PRTDs) monitor the balance temperature profile.
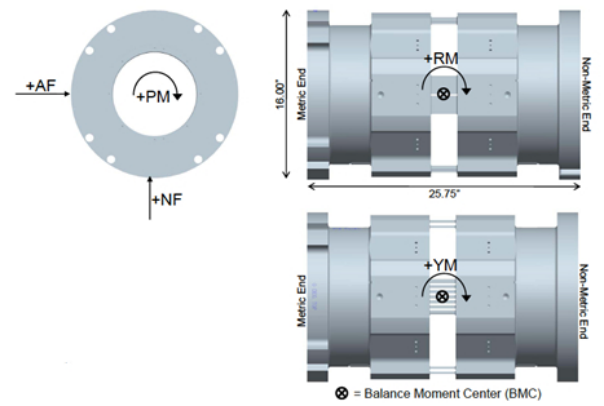

Figure 3. NTF-117S Balance

\begin{tabular}{|lr|rr|rr|}
\hline \multicolumn{2}{|c|}{ Component } & \multicolumn{2}{c|}{ NTF-114S } & \multicolumn{2}{c|}{ NTF-117S } \\
\hline Normal Force & lbs (N) & 6,100 & $(27,134)$ & 12,000 & $(53,379)$ \\
\hline Axial Force & lbs (N) & 1,000 & $(4,448)$ & 1,800 & $(8,007)$ \\
\hline Pitching Moment & lbs-in (N-m) & 70,000 & $(7,909)$ & 90,000 & $(10,169)$ \\
\hline Rolling Moment & lbs-in (N-m) & 350,000 & $(39,545)$ & 669,000 & $(7,558)$ \\
\hline Yawing Moment & lbs-in (N-m) & 76,000 & $(8,587)$ & 100,350 & $(11,338)$ \\
\hline
\end{tabular}

Table 1. Semi-span Balance Load comparison

These temperature sensors are strategically located to provide a global temperature profile as well as localized measurements near the strain gages. The balance design also contains a two-axis on-board accelerometer that provides an absolute reference of the balance attitude. The on-board accelerometers also provide a direct transfer of the balance calibration coordinate system to the wind tunnel model coordinate system. This is especially important since a flow angularity technique has not been developed for semi-span testing, and therefore the offset between the balance axes and the model axes must be mechanically determined.

The design requirements of the NTF-117S were also unique in the area of stiffness. In this case, model dynamics were not the driving factor for the stiffness requirement. The stiffness requirement was due to the unique assembly of the semi-span model system. This assembly requires a minimization of the pitching moment deflection of the metric portion of the model relative to the non-metric standoff. In this system there is a non-contacting seal between the model standoff (nonmetric) and the model fuselage (metric). A high torsional (pitching moment) stiffness of the balance was requested to maintain this gap under aerodynamic loading.

During tunnel operations, the balance is heated and maintained at room temperature or above using the Sidewall Mount Support System (Fig 4). See reference 3. Since this "hot-balance" concept has been adopted; the calibration of the semi-span balances includes a complete room temperature calibration and primary calibration at $150^{\circ} \mathrm{F}$. The elevated temperature calibration is used to determine coefficients that compensate for the change in sensitivity as a function of temperature.

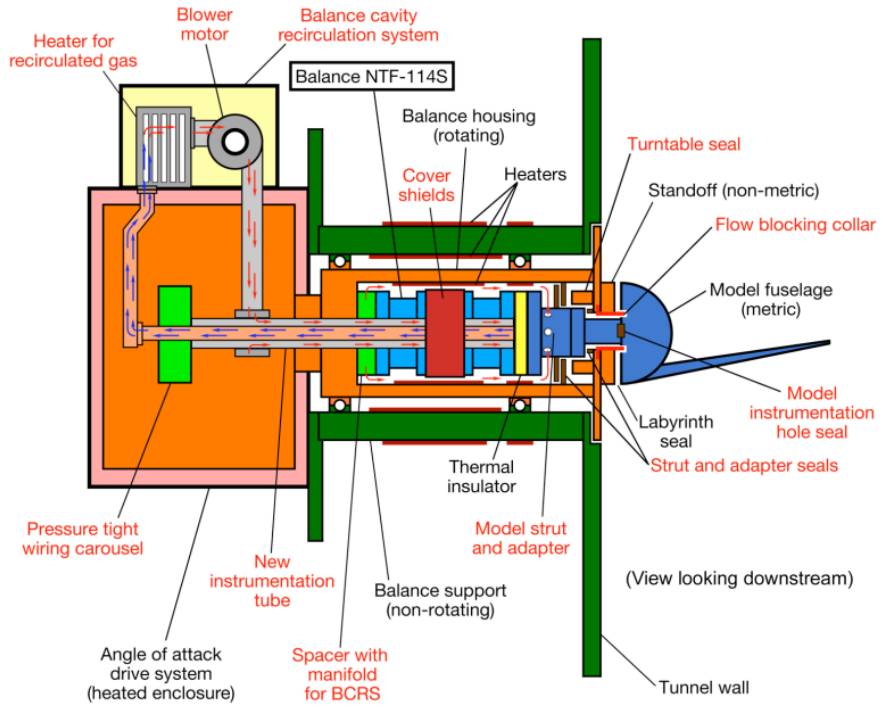

Figure 4. Sidewall Mount Support System (SMSS) 
The design and fabrication of this second generation NTF semi-span balance has been completed. This balance will provide enhanced force measurement capability for continued investigations of high-lift systems of aircraft at near flight Reynolds numbers.

\section{Semi-Span Model Check Load Stand}

A new load frame was required that is capable of supporting check-load on semi-span models and balances that are mounted internally to the Sidewall Mechanism Support Structure (SMSS). See Fig 5. The motivation behind this project was to provide the NTF with a permanent in-house capability for check-loading semi-span balances (and semi-span models) up to full-scale design loads. A limited check-load capability has existed for the SMSS however load capacity was very limited. The original load rig was the shipping fixture of the SMSS and not designed for check-loads. It also provides intermittent calibration capability for semi-span balances. The check-load stand is designed such that it allows for transporting the SMSS from the model build-up bay to the tunnel. The structure is a weldment utilizing readily available materials. See reference 4.

To be compatible with existing facility structure and interfaces the following requirements were imposed:

1. Load stand/cart must retain the same basic volume as current cart design

2. Air casters must retain same nominal separation distance within \pm 2 in $(5 \mathrm{~cm})$

3. Weight of stand/cart should not exceed 5,000 lbs $(2,268 \mathrm{Kg})$

4. Maintain flatness of interface to 0.050 in $(1.27 \mathrm{~mm})$ across all 4 surfaces

5. Design to allow for loading up to $\mathrm{NF}=27,000 \mathrm{lb}$ $(120,102 \mathrm{~N}) \& \mathrm{PM}=150,000$ in-lb $16,948 \mathrm{~N}-\mathrm{m})$ loads at a distance of 43 in $(1.09 \mathrm{~m})$ away from the SMSS mounting plane interface.

6. Acceptable FOS $>2.0$

7. Load Frame to be permanently located in Bay \#1

8. Modify bay to accept secure mounting to floor during loading

9. Allows for the routing / bridging of high pressure air lines

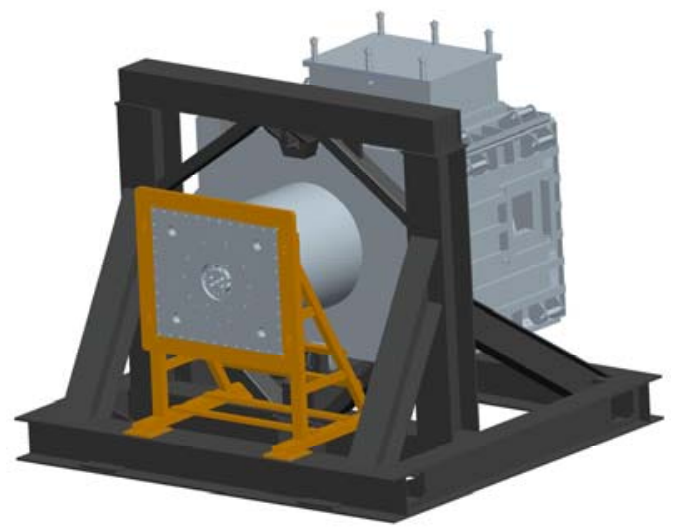

Figure 5. SMSS Check Load Stand

During the check loading process, a calibration interface is mounted to the top-hat. Calibration hardware has been designed and constructed to allow for applying loads to the balance, either via dead weights applied in the basement below Bay \#1, or with hydraulic actuators. The inner turntable inside the SMSS can be rotated such that both NF and AF components of the balance can be check-loaded via hanging a dead weight from the metric end of the balance.

\section{High Pressure Air System}

The addition of a high Reynolds number Model Flow-Control/Propulsion Simulation test capability to the NTF provides a unique world class highReynolds number test capability. This enhanced testing capability is well suited for research in propulsion airframe integration studies, circulation control high-lift concepts, powered lift, and cruise separation flow control. See reference 5.

To achieve this capability, a dual channel high pressure air system consisting of two independently controllable high

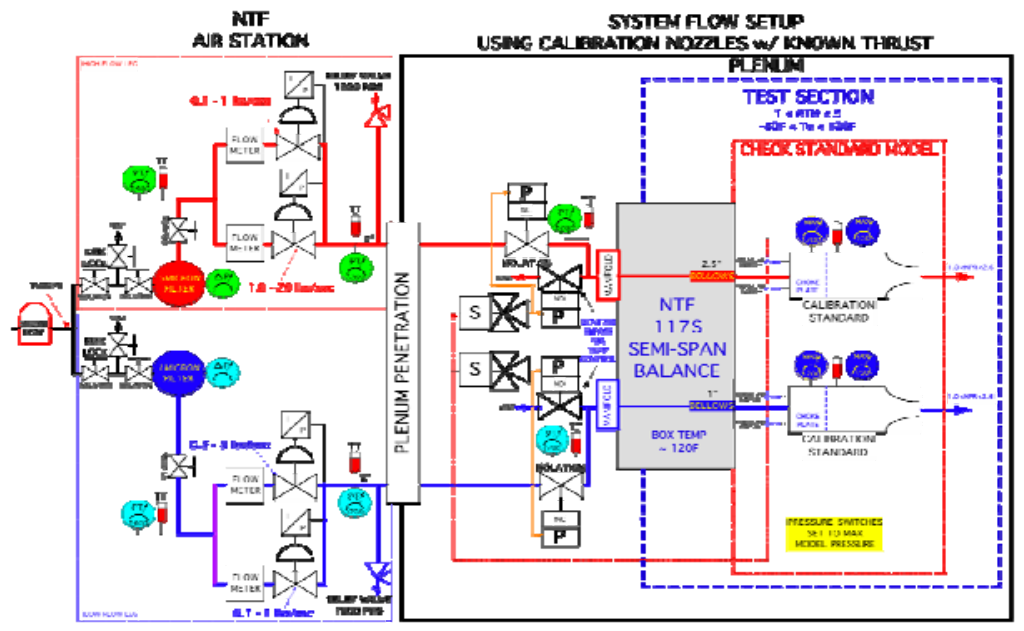

Figure 6. NTF Dual Channel High Pressure Air System 
pressure air lines have been designed, manufactured and installed into NTF. (Fig. 6). Each line has the capability to reduce the incoming, dry 2000 psig air to $300-800$ psig for the low flow line and 800-1275 psig for the high flow line. The high flow line provides $0.1-20.0 \mathrm{lbm} / \mathrm{sec}$ and the low flow line delivers $0.1-8.0 \mathrm{lbm} / \mathrm{sec}$ to the model. The high and low flow lines use five (5) and one (1) micron filters respectively to ensure a clean air supply to the model. These air lines enter the NTF shell separately and route to the Sidewall Model Support System (SMSS) using either the NTF114S or the NTF117S five component balance. The air supply lines are routed through the center of the balance through concentric bellows to an interface with the model. (Fig. 7)

Initial operations of the facility are being limited to total pressure of 5 atmospheres and a total temperature of $-50^{\circ} \mathrm{F}$ when the air station is being used to avoid the formation of frost in the tunnel circuit. The air station provides pre-heated

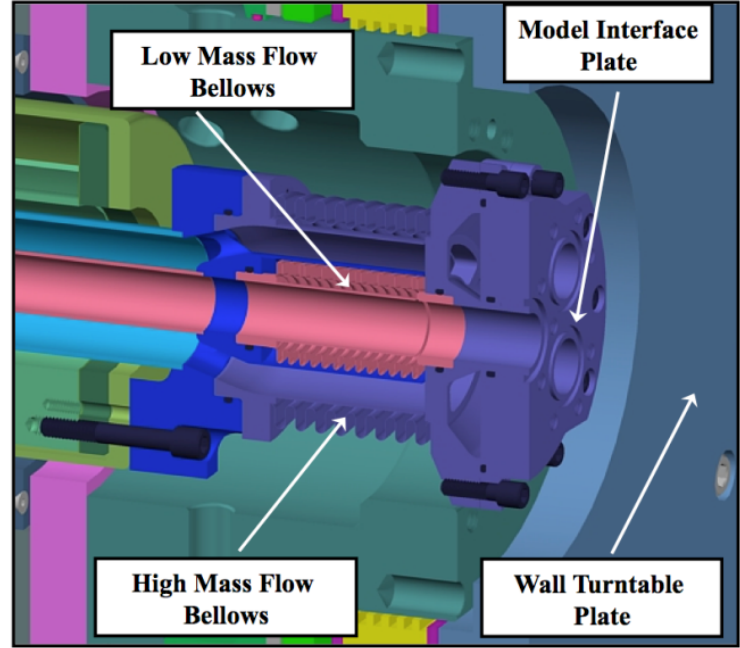

Figure 7. Concentric Bellows Interface high-pressure air to the model, thus low temperature control of the jet is obtained through Joule Thompson effects and heat transfer through conduction of the pipes that are exposed to the cold temperatures inside the facility plenum from $-50^{\circ} \mathrm{F}$ to $+120^{\circ} \mathrm{F}$.

Incorporated into the air delivery system is a fast acting model protection system. The isolation and vent system can be adjusted for maximum internal pressures that vary from 400 to 1200 psig to match the design pressure limits of any given wind tunnel model. In the event of an inadvertent pressure spike, the model over-pressure protection system automatically isolates and vents the wind tunnel model, and provides a command to shut down and vent the highpressure air delivery system. This isolation and venting of the wind tunnel model has a reaction time of one second or less. The

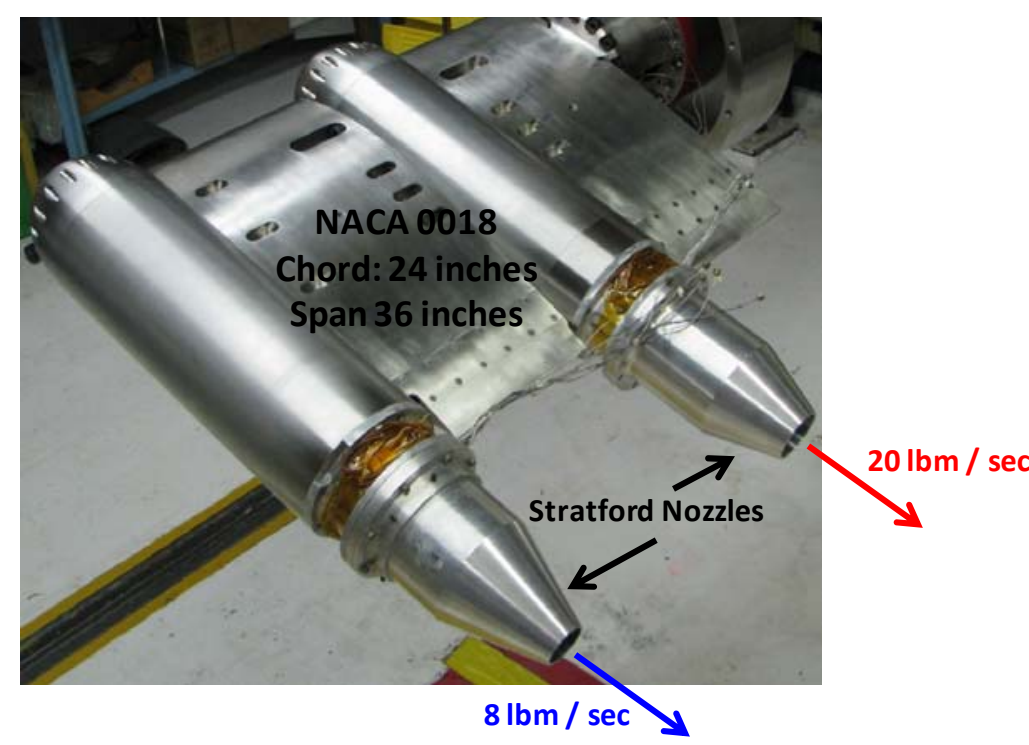

Figure 8. Air System Checkout Model ventilation valves can also be used to precondition the air temperature of the system, efficiently allowing this procedure to occur while the wind tunnel is being brought onto condition.

To verify and validate the air station test envelope, a standard calibration model was developed. This model uses readily available Stratford calibration nozzles from the NASA inventory that have known thrust characteristics mounted to a NACA 0018 symmetrical airfoil sturcture. (Fig 8). The maximum flow rate for either leg occurs at the lowest free stream Mach number and highest free stream static pressure. The internal model pressure is limited to 1200 psig and is based on the high pressure limit of the air station piping system. The maximum mass flow rate for the high mass flow leg is $20 \mathrm{lbm} / \mathrm{sec}$.

The initial checkout test of the new air system has been successfully completed in November 2010. 


\section{Model Dynamics Damping System}

To reduce the amount and magnitude of aerodynamically induced model dynamics, an active Model Dynamics Damping System was developed. As a test bed for this effort the NTF Common Research Model (CRM) was utilized for development and check out purposes. See references 6 and 7.

The front, upswept, sting for this configuration is fabricated from Vascomax 200/250, the damper body is INVAR36, and the stub-sting at the rear is made of A286. The INVAR36 and A286 have vastly different coefficients of thermal expansion. The damper consists of twelve (12) 11,000-lb (48,930-N) piezoceramic actuators made of PZT orthogonally placed around the adapter in 4 groups of three actuators each. (Fig. 9). The actuators are driven by wide-band drive amplifiers capable of driving 30-microfarad actuators for the damper.

The basic principle and function of a damper is to generate a dissipating energy based on the stored energy in the sting. For the CRM sting system, 12 joules are released in 25 milliseconds (1/4th of first mode frequency of $10 \mathrm{~Hz}-100 \mathrm{~ms}$ ) equating to a power of 600 watts. Piezo devices can absorb this energy as current of appropriate polarity as determined by balance feedback, using an appropriate control laws driven by balance moments. The piezo cluster thus has to dissipate 12 joules in 25 milliseconds. (At $10 \mathrm{~Hz}$ sting mode, quarter wave occurs in $25 \mathrm{~ms})$. At a voltage rate of $24,000 \mathrm{~V} / \mathrm{s},(600$ volts in $25 \mathrm{~ms}$ ) the flow of current into the 15 microfarad cluster is 0.36

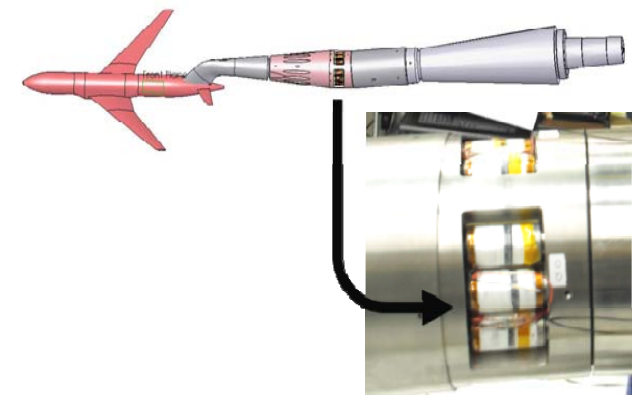

Figure 9. Dynamic Damping System amps, and this amounts to 2.7 watts or 5.4 watts for pitch axis for max energy of 12 joules.

During January 2010, the damper system was installed at NTF and tested in air mode. The Mach number range was from 0.70 to 0.92 . Dynamic Pressure varied between 1,200 and 1,400 psf (57.5 and 67.0 KPa). Angle of attack range varied from $-3^{\circ}$ to $+12^{\circ}$. Three model configurations, wing \& fuselage, wing-fuselage with nacelle, and wing-fuselage with tail were tested. The model encountered severe buffet at angles above $6^{\circ}$.

Figure 10 illustrates damper performance by comparing

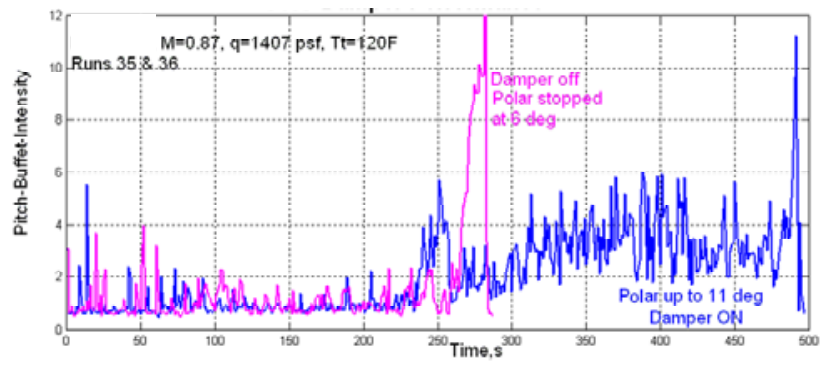

Figure 10. Damper Performance damper On and Off runs. Pitch buffet Intensity is defined as an rms value of normal force fluctuations normalized by flow fluctuations without buffet at low angles of attack. With damper off, the pitch buffet intensity was roughly ten (10), while with damper on it dropped to about four (4), nearly a three-fold improvement. Runs without the damper were forced to terminate at $\sim 6^{\circ}$ angle of attack. Runs with the damper active achieved $\sim 12^{\circ}$ angles.

The system was also checked out at cryogenic temperatures. Even at $-250^{\circ} \mathrm{F}\left(-157^{\circ} \mathrm{C}\right)$, the actuators work well except that the energy level dropped to $20 \%$ of the level at ambient conditions; hence they were not as effective. The loss of capacitance from $15 \mu \mathrm{F}$ down to $3 \mu \mathrm{F}$ at $-250^{\circ} \mathrm{F}$ has resulted in a $80 \%$ loss of performance in energy capability; hence damper performance has been poor under cryogenic conditions. In future designs it will be necessary to find methods to keep the piezo actuators warm so that damping functions work at designed efficiency.

\section{Data Acquisition System Upgrade}

The existing NTF Data Acquisition System (DAS) consists of three systems; a Research Computer System (RCS) DAS, a Process Computer System (PCS) DAS and a Model Preparation Area (MPA) DAS (Fig 11). These systems are based on the 1992 MODCOMP Real/Star systems (VME Bus architecture using a MODCOMP proprietary Operating System) platform that is no longer supported by industry, has limited expandability and does not have the capability to be simply upgraded to meet the increasing research needs for data quality that requires advanced data collection and analysis test techniques, data storage capability and system security requirements. Additionally, all three systems, hardware and software are obsolete and beyond their expected life with a limited number of spares/replacement parts and, therefore, must be replaced. 
The objective of this project is to improve the technical capability of the NTF in providing continued high quality high Reynolds number testing by upgrading the existing DAS computers and software. This upgrade will improve the NTF's technical viability in the form of advanced data collection, analysis and signal processing techniques, while assuring future cost effective systems for maintainability, reliability and data and physical security in integrated commercially available systems. This upgrade will allow NTF to improve the data quality, enhance current testing techniques, support new testing techniques, and provide continued support of advanced testing requirements.

System definitions are as follows:

Research Computer System (RCS): The RCS DAS performs the data acquisition and calculations for tunnel parameters, test article measurements and various research specific measurements.

Process Computing System (PCS): The PCS DAS performs as the plant state monitor and logging historian.

Model Preparation Area (MPA): The MPA DAS performs data acquisition and calculations for signals generated in the Model Preparation Area.

Dynamic Data Acquisition System (DDAS): The DDAS will be an integral part of the facility research data collection process on RCS. The DDAS will collect data simultaneously with RCS at higher sample rates (up to $5 \mathrm{KHz}$ ) on 32 analog channels at 24-bit resolution (allowing real-time spectral analysis up to $512 \mathrm{~Hz}$ ) and concurrently collect data from RCS and PCS to time correlate RCS and PCS data to the DDAS data.

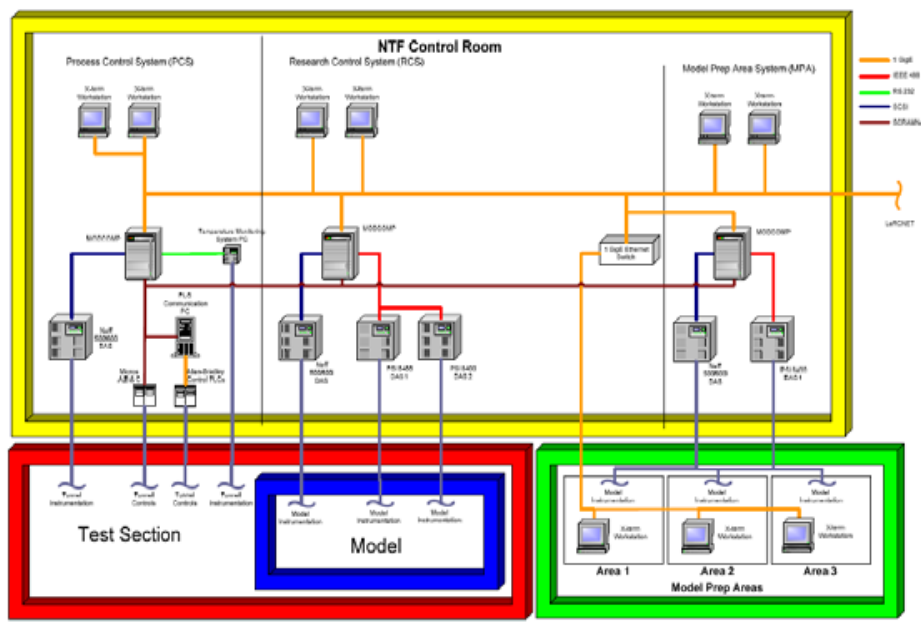

Figure 11. Current NTF DAS System Architecture

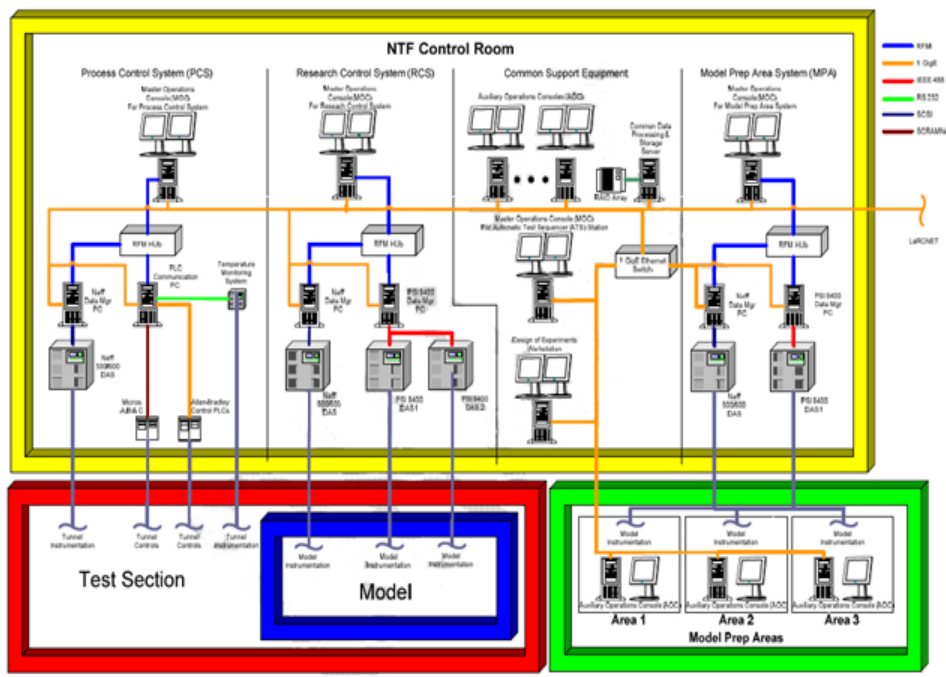

Figure 12. New NTF DAS System Architecture

An Automatic Test Sequencer (ATS) will be implemented to facilitate automating the "Run" test matrix, and support future testing techniques such as conditional data sampling methods, continuous sweep data collection and Design of Experiments (DOE).

This DAS Project involves the design, purchase, build, integration, installation and verification of a new DAS System at the NTF by replacing the RCS DAS, the PCS DAS, and the MPA DAS, and integrates the DDAS into the tunnel DAS systems operations (Fig 12). The new systems will be compatible with all current facility ancillary systems interfaces which include the Micro Controls Systems, NEFF Instrument Corporation Analog to Digital Interfaces, Pressure Systems Inc. Flow Reference System, PSI-8400 Pressure Measurement Systems, Kaye temperature monitoring system, Allen-Bradley Programmable Logic Controllers, and Video Data Systems. In addition, the replacement system will be adaptable to current industry standards to allow for future upgrades. An example of future upgrades that the NTF may pursue includes the replacement of the current NEFF Instrument Corporation Analog to Digital Interfaces, the Flow Reference Systems and the Controls Systems; however, actual replacement of such systems is not within the scope of this project. See reference 8 . 
The NTF DAS Upgrade Project will replace the current computer systems. Improvements and upgrades will be by-products of using updated equipment and software. The project is associated with a long term plan to provide a common hardware/software platform for staff sharing between other test facilities for commonality across LaRC. The NTF DAS will be the primary system that will acquire, process, monitor, display, store, and provide final data products for the NTF wind tunnel. Other auxiliary systems that support the testing process will interface with the NTF DAS. These may include test article control systems, video systems, facility control systems, and in-house or customer-supplied test peculiar data systems.

The DAS upgrade approach, system development, and implementation is being accomplished in five distinct phases.

Phase 1 - Design Study:

Perform a Design Study that includes the Project Requirements and Conceptual Design which clearly shows the project definition, scope and performance requirements, a requirements document for the new systems and an assessment of the new systems capabilities.

Phase 2 - Preliminary Design Review (PDR):

Using the approved Design Study Report and Work Plan for Phase 2 to develop a Preliminary Design Review package for the new DAS. The package included a draft Systems Requirements Document and cost/schedule/resource status and project management, risk and configuration management plans.

Phase 3 - Critical Design Review (CDR):

Using the approved Preliminary Design Review package, Design Study Report to develop a complete Critical Design Review package, including final Systems Requirements Document, integrated system design documentation, updated cost/schedule/resource status, project management, risk, life cycle maintenance and configuration management plans.

Phase 4 - Equipment, Software, \& Bench Top Integration:

Proceed with development and/or acquisition of appropriate components (equipment, hardware and software) for system development, component integration, system integration and testing. The successful execution of the Demonstration and Verification Test Plan with results documented against System Requirements will be performed.

Phase 5 - Facility Installation:

Facility operations will execute the Installation and Acceptance Testing Plans for installing and checkout the new DAS at the NTF. The new integrated DAS system that has been verified through an acceptance test process and all supporting documentation (e.g., drawings, manual, schematics, calibration records) that are field verified, archived and under configuration control, along with a completed Operational Readiness Review package will be delivered. Additionally, detailed training and training documentation on the operations and maintenance of the new DAS systems will also occur.

As of January 2011, this DAS upgrade is currently in Phase 4. The Jacobs Technology Test SLATE (Software for Laboratory and Automated Test Environments) application has been selected as the basis for this upgrade. Test SLATE is a comprehensive, easy-to-use test control and measurement process management application. It is a Windows ${ }^{\circledR}$-based, highly flexible test measurement and control software that requires no proprietary hardware and works with nearly any control or measurement device or system, regardless of make or model. More importantly, this software is currently in use at other LaRC facilities providing commonality. This project is on track to be completed by September 2011 and is being funded through the American Recovery and Reinvestment Act of 2009 (ARRA).

\section{Facility Automation System Upgrade}

The NTF Facility Automation System (FAS) is a 1992 vintage system and are consist of components that are no longer commercially available. The existing NTF tunnel control systems consist of three microprocessor computer systems identified as $\mathrm{A}, \mathrm{B}$, and $\mathrm{C}$ that perform the functions of tunnel pressure controller, tunnel temperature controller, Mach number controller, and model position controller. The existing microprocessors include analog safety interlock controls, as well as supervisory functions for controlling the tunnel operations. This control system interfaces to the facility through Programmable Logic Controllers (PLC). To ensure continued trouble free operation these systems require replacement (Fig 13). 
The objective of this project is to improve the technical viability of the NTF in providing continued high-quality, high Reynolds number testing by installing a new tunnel controls system, replacing the existing safety interlock systems, determining critical system replacements, developing a tunnel simulation tool and conducting a demonstration and validation test. This entire project will implement high performance productivity enhancements to the NTF that improves the data quality, enhance current testing techniques, support new testing techniques, provides better maintainability and reliability and provide the LaRC continued support of advanced testing requirements. See reference 9.

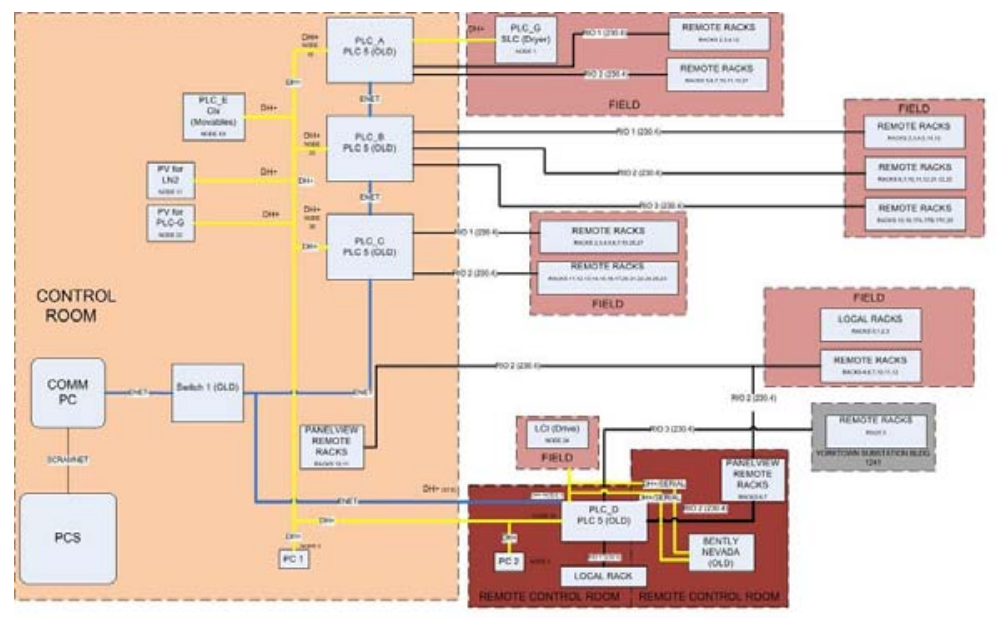

Figure 13 . Current NTF FAS System Architecture

This effort has been divided into five subtasks, as described below. The first four subtasks can be completed independently, but all are required to be completed prior to the final Demonstration and Verification test identified in Subtask 5. Consideration is being given during the final integration, checkout, and verification of each subtask to minimize facility downtime.

Subtask 1: Replace existing NTF Controls System Microprocessors.

The existing NTF Controls System Microprocessors (1992 vintage) consisting of Microprocessors A, B, and $\mathrm{C}$, user interfaces, and all controls and interlock functions will be replaced with an existing single Programmable Logic Controller (PLC), Industrial Personal Computer $(\mathrm{PC})$, and Panel View ${ }^{\circledR}$ Human Machine Interfaces (HMI).

Subtask 2: Replace existing NTF Programmable Logic Controllers.

The existing PLC A, B, C, and D will be upgraded from the AllenBradley Series 5 to ControLogix 5000 (Fig 15). Each existing PLC

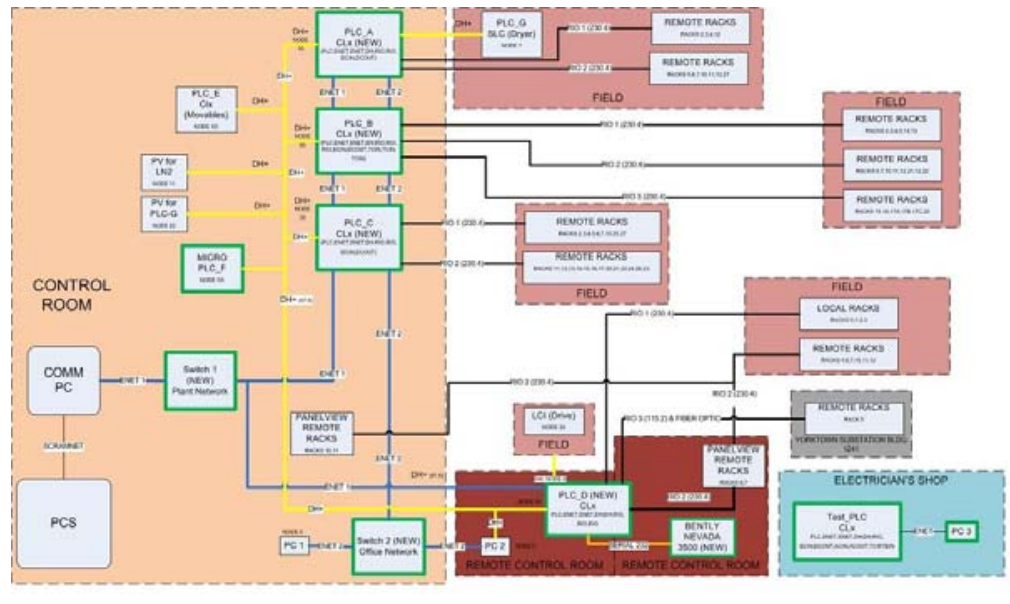

Figure 14. New NTF FAS System Architecture will be replaced one-for-one with a ControLogix 5000 in order to maintain the current relationship on logic solving, allowing for parallel inputs and series outputs as in the existing operating PLCs.

Subtask 3: Design Study for Replacement PSI Flow Reference System.

The current NTF Flow Reference System (FRS) is a critical data quality measurement device that provides precision absolute and differential pressure measurements that are used in determining the tunnel Mach number. Pressure Systems, Inc. has discontinued the FRS and no longer carries replacement or spare parts. Additionally, they have chosen not to offer a replacement or upgrade system for the FRS. As a critical component of this subtask, a viable replacement alternative that meets or exceeds the current performance of the current system will be recommended.

Subtask 4: Software-based Simulation Model of the NTF tunnel processes and control systems.

The NTF has complex control systems with strong interactions and dependencies. For example, Mach number control is affected by tunnel pressure, temperature, fan pressure ratio, and whether the tunnel is operating with air or nitrogen as the test gas. Optimization of the current control systems has been limited by the complexity and wide range of facility operational conditions, high operational expenses, risks, and extensive commitments of tunnel operational time. As a result, little new optimization or algorithm 
development has taken place. A software-based simulation model is being developed and implemented that will allow for this necessary optimization development work without the need to operate the tunnel.

Subtask 5: Demonstration and Verification Tests: This effort contains three subtasks (Subtask 1 Controls Upgrade, Subtask 2 - Programmable Logic Controller Replacement, and Subtask 3 Simulation Model) that require a demonstration of the operations and verification of performance of the systems developed under each subtask. Two tests will be conducted at the facility, to meet all the demonstration and performance verification requirements of this upgrade effort. These two tests will repeat the "NTF Check Standard Test" and also include a limited number of additional Cryogenic Operations test conditions to cover the cryogenic

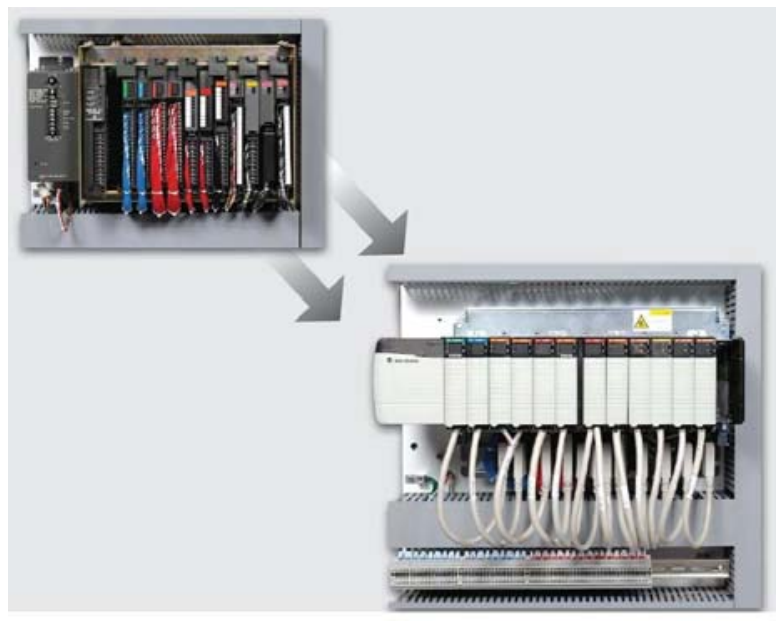

Figure 15. PLC Replacement operational capability of the facility. The first test was conducted in March 2010 to obtain a baseline of the facility operations (both Air and Cryogenic Operations). After the completion of the Controls Upgrade, PLC Replacement, and the Simulation Model, a second test, identical to the first, will be conducted thereby providing a measurable metric of the improvements made by the NTF FAS upgrade.

As of January 2011, this FAS upgrade has completed the Critical Design Reviews (CDR) for Subtasks 1 and 2, and Subtasks 3 and 4 are in process. This project is on track to be completed by September 2011 and is being funded through ARRA.

\section{Reliability Assessment}

Facility reliability (operational readiness) is a key metric for all service providers. The annual goal of NASA's Aeronautics Test Program (ATP) is to "Deliver at least 94\% of "on-time availability" for all operations and research facilities. On-time availability" is defined as cumulative test hours divided by the sum of cumulative test hours plus unplanned maintenance and repair hours. The intent is to capture the effect of unplanned maintenance and repair events on scheduled tests. Unplanned maintenance and repair can happen before or during a scheduled test.”

The objective of this effort is to improve the operational reliability of the NTF. To achieve this objective, an operational reliability assessment that provides detailed recommendations for implementation to improve the operational reliability has been performed. Areas (items) were identified to improve the operational reliability of the NTF and to optimize facility investments over the long-term. Facility reliability is sustained through reliability based maintenance strategies including a cost effective blend of preventive (time-based), predictive (condition-based) reactive (breakdown based) and programmed (budget based) maintenance investments. This Project has been divided into two Tasks. Task 1 conducted an overall reliability assessment of the NTF and provides a prioritized list of improvements that can be made. Task 2 will then act on some (or all) of the results from Task 1. Task 1 was divided into three distinct subtasks.

Subtask 1 - Review/Analysis of Lost Time: A detailed review and analysis of operational lost time history of the NTF has been performed. This review and analysis identified the operational lost time and the associated cost impact per lost time per system over the last four fiscal years (2006, 2007, 2008, \& 2009).

Subtask 2 - On-Site Condition Assessment: An on-site system condition assessment has been conducted and documented to evaluate the current condition of major facility systems and subsystems. The physical condition of each major system and associated subsystems was assessed; the effectiveness of the current maintenance program will be evaluated, spare parts inventory and systems operations will be investigated; the systems will be assessed against the "industry standards" toward maintenance and reliability of similar equipment. This Condition Assessment Report included an evaluation of the systems with regard to safety of equipment, safety of workforce, system reliability, an estimation of remaining useful life and likelihood and cost of a system or component failure. 
Subtask 3 - Recommendations and Review: Critical data was collected, analyzed, and compiled and results from the Review and Analysis of Lost Time (Subtask 1) and the On-Site Condition Assessment (Subtask 2).

The Final Recommendations Report included a summary of the project scope; description, approach, findings and detailed recommendations in priority order that are considered necessary to improve the NTF's reliability in priority order necessary to improve reliability and reduce lost time and costs. The actual findings report are beyond the scope of this summary presentation. These final recommendations from Task 1 formed the basis to initiate Task 2 which will implement the findings of Task 1 . See reference 10.

NASA has reviewed the Reliability Assessment Study final report and determined that two items (plus four optional items) from the report should be implemented, considering available budgets and schedules. These two items and four optional items are listed below:

\section{A. Replacement of Main Pitch Hydraulics Pump}

The NTF uses a hydraulic actuator to move the model under test in pitch (nose up or down). The Main Pump is a high pressure, high volume pump used to provide faster angle sweeps (Fig 16). This pump is a nine cylinder axial piston pump. Recent testing of the pump shows that the pump is beginning to fail. The loss of this pump would bring to a halt all testing of full-span models in the NTF. There is no spare in the facility with which to replace this pump. A new pump is needed immediately.

\section{B. Replacement and Maintenance of the Drive Motor Shaft Stein Seal Carbon Inserts}

The Stein Seal acts as the pressure barrier between the tunnel and outside at the drive shaft penetrations (Fig 17). It consists of a series of chambers along the shaft each incrementally stepping down in pressure. These chambers are 'sealed' along the shaft with by several sets of carbon ring inserts that ride on the drive shaft outer surface. These carbon inserts are rated for an operating lifespan of 4000 hours at which point they are to be removed and replaced in accordance with the standard NTF maintenance plan for the seals. These seals have not been replaced in 9 years and are past due for replacement. Additionally, if the seal leaks, cryogenic Nitrogen gas from the tunnel could leak out causing a safety hazard in the facility. Therefore, these new carbon inserts are needed immediately to ensure safe operations of the facility.

C. (Optional Item) Spare hardware for NTF Fan Drive Motor $3^{\text {rd }}$ and $5^{\text {th }}$ Harmonic Filter

The drive motor for the NTF Fan uses a series of passive harmonic filters to condition the electrical power used by the main drive. When one of the

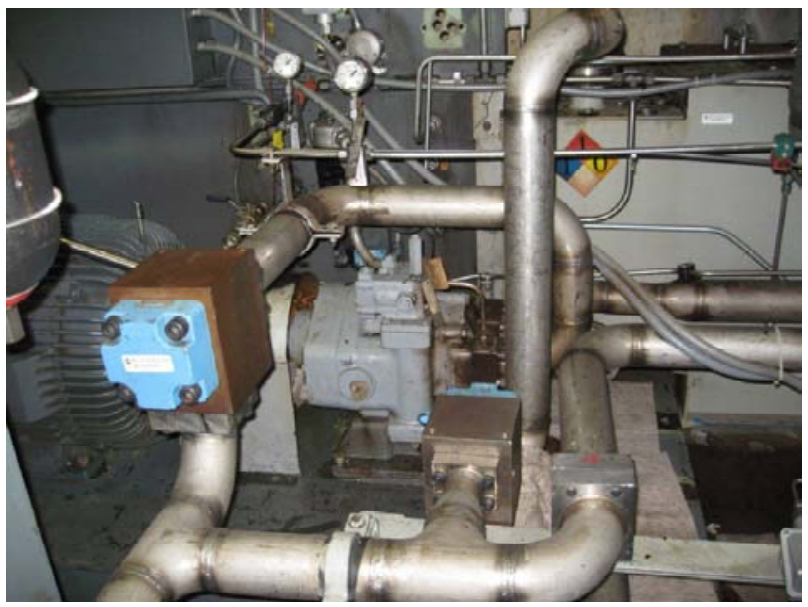

Figure 16. Pitch Pump

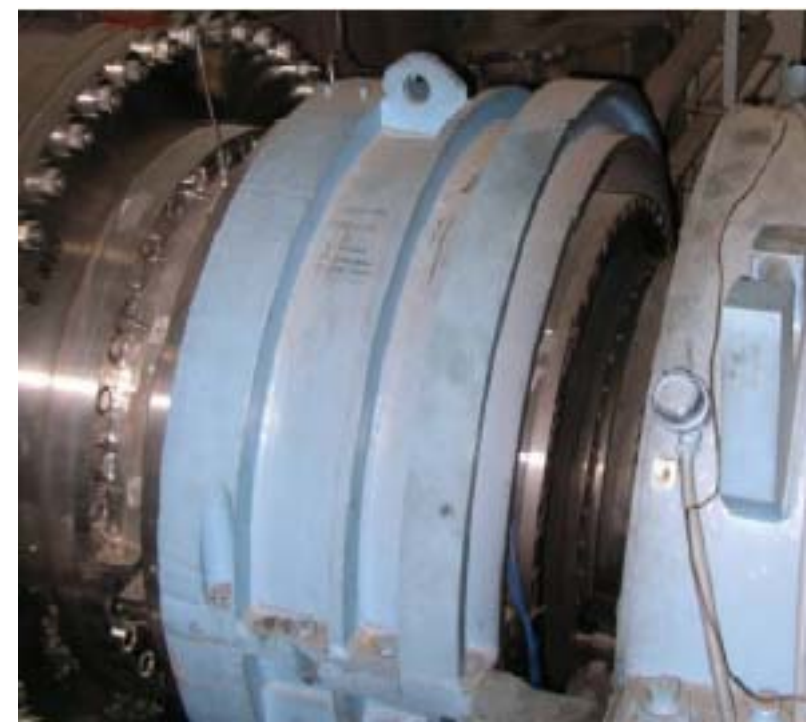

Figure 17 . Stein Seal

harmonic filters fails, the drive motor (and hence the facility) is down and tests cannot be run until the failed component is replaced. Two of the three reactors in the $3^{\text {rd }}$ harmonic filter have failed and had to be replaced. The third reactor is still in place but is of questionable health. The capacitors in the $5^{\text {th }}$ harmonic filter are in 
poor health. These parts are long lead time items. To minimize facility lost test time, spare components are needed immediately to assure reliability of the facility.

\section{D. (Optional Item) New Control Room Security System Card Readers}

The NTF currently uses a standalone card key security system to prevent unauthorized personnel from entering potentially low Oxygen environments when the facility is running with Nitrogen in the tunnel. The existing entry system dates to the late 1980's and uses obsolete computer equipment, software and readers. The existing system does not meet and cannot be made to meet the security requirements levied from NASA HQ. As part of the NASA Agency security program, new center-wide card key systems have been installed. The existing card key system is not and cannot be made compatible with the new Center-wide system. New access door readers are needed to replace the existing readers and to be connected to the new Center-wide system. To be compatible with NASA security and safety requirements, replacement of the existing system is required.

\section{E. (Optional Item) Spare Hygrometers}

Monitoring the moisture content of the test gas (air or nitrogen) in the NTF is critical due to the cryogenic operations in the facility. Moisture contained in the test gas will, when the temperature of the gas is lowered to test conditions, first condense out as a liquid and then freeze as the temperature gets below the freezing point for water. This condensed liquid and then ice affects the model geometry leading to erroneous test data. Moisture content within the tunnel is monitored by several hygrometers placed in key areas of the tunnel circuit. The NTF currently has no spare hygrometers. Annual calibration of these sensors is required and must be coordinated to periods when the facility has no ongoing testing. On occasion, delays in the calibration process have caused lost test time as the tunnel cannot run without calibrated hygrometers. Spares are required to reduce potential tunnel lost test time.

\section{F. (Optional Item) Spare Main Drive Control Hardware}

The NTF main drive motor was installed in 1997. The motor is now 13 years old. The manufacturer has announced that the drive control hardware is obsolete and is no longer supported. This hardware is critical to the operation of the Fan Drive motor and failure of one of these components causes the facility not to be able to test. Until the existing drive control hardware is replaced with modern equipment, spare components are needed immediately to assure reliability of the facility.

\section{Conclusion}

The NASA Langley Research Center has been engaged in a two year effort to improve the quality and reliability of the National Transonic Facility. These projects represent a more than $\$ 12 \mathrm{M}$ investment into facility's systems to ensure that NTF will continue to produce high quality data in a safe, efficient, and cost effective manner to satisfy the NTF's worldwide customer base. All work will be completed by September 2011.

\section{References}

\footnotetext{
${ }^{1}$ Bissett, O. W., Hudson, C. M., "Selected Major Modifications To The National Transonic Facility," 47 $7^{\text {th }}$ AIAA Aerospace Sciences Meeting, Paper AIAA-2009-419, 5 - 8 January 2009, Orlando, Florida

${ }^{2}$ Parker,P. A., "Cryogenic Balance Technology at the National Transonic Facility", $39^{\text {th }}$ AIAA Aerospace Sciences Meeting, Paper AIAA-2001-758, January 8-11, 2001 Reno, NV

${ }^{3}$ G. M. Gatlin, G. M, Tomek, W. G.,. Payne, F. M., Griffiths R. C., "Recent Improvements in Semi-Span Testing at the National Transonic Facility (Invited)", $44^{\text {th }}$ AIAA Aerospace Sciences Meeting and Exhibit, Paper AIAA-2006-508, January $9-12,2006$ Reno, Nevada

${ }^{4}$ Lynn, C., "NTF SMSS Check-Load Stand/Cart Design Review”, Aeronautics Systems Engineering Branch, NASA LaRC, March 9, 2010, Hampton, VA

${ }^{5}$ Milholen II, W. E., Jones, G.S., Cagle, C.M., "NASA High-Reynolds Number Circulation Control Research - Overview of CFD and Planned Experiments (Invited)" $48^{\text {th }}$ AIAA Aerospace Sciences Meeting Including the New Horizons Forum and Aerospace Exposition, Paper AIAA-2010-344, 4 - 7 January 2010, Orlando, Florida
} 
${ }^{6}$ Balakrishna, S., Butler, D. H., White, R., Kilgore, W. A., “Active Damping of Sting Vibrations in Transonic Wind Tunnel Testing," $46^{\text {th }}$ AIAA Aerospace Sciences Meeting and Exhibit, Paper AIAA-2008-840, 7 - 10 January 2008, Reno, Nevada

${ }^{7}$ Balakrishna, S., Acheson, M., "Cryogenic Tunnel Performance Analysis and Operational Enhancements Semiannual Summary Report”, 5 June - 4 December, 2009,

${ }^{8}$ Lowrance, K., “NTF DAS Replacement Software Project Management Plan V1.0, AE02545”, Jacobs Technology Group, September 20, 2010, Tullahoma, TN

${ }^{9}$ Beavan, L., "Upgrade of the Tunnels Controls System for the National Transonic Facility (NTF), AE02544", Jacobs ROME, January 29, 2010, Hampton, VA

${ }^{10}$ Treece, M., "Operational reliability Assessment for the National Transonic Facility (NTF), AE02546”, Jacobs ROME, August 23, 2010, Hampton, VA 